\title{
Progeny Testing Preceded by Phenotypic Pre-selection - Timing Considerations
}

\author{
By D. DANusevičruUs ${ }^{1,2^{*}}$ and D. LINDGREN ${ }^{3}$
}

(Received $15^{\text {th }}$ September 2003)

\begin{abstract}
Progeny-testing is a common element in tree breeding. It takes long time until trees reach the sexual maturity. That time could be used for field testing followed by progeny-test of the selected phenotypes (two-stage strategy), or the time until mating could be reduced by forcing early flowering (singlestage strategy). Benefit of phenotypic pre-selection followed by progeny testing in long-term breeding was assessed as a function of the age at the pre-selection by the aid of a deterministic tree breeding simulator. As a criterion of goodness of a breeding program, annual progress in group merit $(G M / Y$-refers to the rate of change in the average of genetic gain and gene diversity) at a total budget constraint was used. For simplicity, a long-term program with balanced selection was studied. Scenarios with different genetic parameters, cost and time components were evaluated and optimised for resource allocation. At the optimum age of mating for progeny test, two-stage Phenotype/Progeny strategy generated higher $G M / Y$ than singlestage Progeny strategy at the age of mating for progeny test equal to three years, except for a typical scenario with weak JM correlation, low heritability and long rotation time. High heritability, short rotation and strong J-M genetic correlation favoured phenotypic pre-selection. Optimum age for phenotypic pre-selection varied from 6 to 17 years and the percentage of $G M / Y$ lost in comparison to the maximum due to delay of mating for the progeny test until age 15 and 25 years ranged from 0 to $14 \%$ and from 1 to $29 \%$, respectively. In the case of low heritability, long rotation, low J-M correlation, high cost for cycling and low budget, early mating age would bring little benefit if compared to mating at the optimum age. We suggest that, in long-term breeding based on progeny testing, investment in phenotypic pre-selection is more beneficial than investment to achieve early flowering to initiate the progeny test early.
\end{abstract}

Key words: annual gain, juvenile-mature correlation, gene diversity, group merit, optimisation, two-stage selection, stage-wise selection, flowering induction.

\section{Introduction}

Selection based on progeny test is used in many tree breeding programs. Its main disadvantages are comparably long breeding cycle time and high costs. A straightforward approach to improve it would be to shorten the age when the candidates become sexually mature. However, early flowering induction is

1) Department of Forest Genetics and Reforestation, Lithuanian Forest Research Institute, LT-4312, Kaunas reg., Lithuania. E-mail: darius.danusevicius@takas.lt. Major part of the study was carried out $\mathrm{at}^{3}$.

2) Department of Silviculture, Faculty of Forestry, Lithuanian Agricultural University, Studentu str., LT-4324, Kaunas-Akademija, Lithuania.

3) Department of Forest Genetics and Plant Physiology, Swedish University of Agricultural Sciences, S-901 83 Umeå, Sweden. E-mail Dag.Lindgren@genfys.slu.se

*) The corresponding author is DARIUS DANUSEviČIUS. The correspondence shall be sent to the following address: Lithuanian Forest Research Institute, Girionys 1, LT-4312, Kaunas reg., Lithuania. E-mail: darius.danusevicius@takas.lt. Fax: +370-37-547-446, Tel. +370-37-547-426 a knowledge and resource demanding procedure, like e.g. glass houses, top grafting or tissue culture (e.g. BRAMLETT et al., 1995; HÄGGMAN et al., 1996; ALMQVist, 2001) and often is not developed enough for a full-scale practical application. Furthermore, our recent study on optimisation of long-term breeding strategies indicated that, under relevant parameters for boreal tree species, it seems often beneficial to use the first decade for phenotypic pre-selection rather than initiate progeny testing earlier (DANUSEVIČIUS and LINDGREN, 2002b). Given the numerous attempts to establish reliable methods for early flowering induction and wide-spread application of progeny testing, it is interesting to investigate under which conditions, if any, early initiation of progeny testing is favourable.

Prediction of optimum value of selection age depends on the function used to predict juvenile-mature (J-M) genetic correlation (WEI and LINDGREN, 2001). Earlier studies optimising the selection age in tree breeding commonly used the LAMBETH's (1980) function to predict J-M genetic correlations (e.g. McKeand, 1988; Burdon, 1989; KING and BuRdon, 1991). However, though being based on numerous trials with several temperate and boreal pine species, this function was developed on the basis of phenotypic correlations and is believed to underestimate the more relevant genetic J-M correlation (RIEMENSCHNEIDER, 1988; BARNES et al., 1992; GWAZE et al., 1997; XIE and YANChuK, 2002). GWAZE et al. (2000) and LAMBETH and DILL (2001) developed a number of J-M correlation functions based on genetic correlations estimated in a large number of trials with Pinus taeda. Predictions based on the above-mentioned functions favour an earlier selection than LAMBETH (1980) function. When LAMBETH (1980) developed the J-M correlation function, the availability of relevant materials close to rotation time was poorer than today, this may also be a reason to have some later functions as alternatives.

In long-term breeding, the emphasis can be predicted to focus on within-family selection, although few forest tree breeding programs has yet reached that stage. The possible added advantages of applying a considerable amount of between family-selection are doubtful, uncertain and minor (Rosvall, 1999). An emphasis on between family selection can lead to a fast exhaustion of gene diversity in the breeding population (WEI, 1995). The key-outputs (like gain and group coancestry) tends to change with a constant amount in each cycle and only after more than about five generations starts the change over cycles to be noticeably different (Rosvall et al., 1999). Thus, the study of a single complete cycle ought to give sufficient predictability for optimisation of long-term breeding for forest trees, where the foreseeable future is just three or five cycles away, and thus progress over a number of generations is approximately cumulative.

A well-founded comparison of testing and selection (cycling) strategies should account for the time and cost efficiency. Group merit per unit of time is an index, which considers gain, diversity and time simultaneously (LINDGREN and MULLIN, 1997; WEI and LINDGREN, 2001). Cost factor can be incorporated by setting relative cost weights for components of alterna- 
tive strategies and comparing them under a budget constraint (DANUSEVIČIIUs and LINDGREN, 2002a). Thus, our study considers four key elements in breeding: gain, diversity, cost and time. Within a breeding cycle, testing and selection can be carried out in one or two stages. Usually, two-stage strategy involves a phenotypic pre-selection followed by reselection based on clonal or progeny testing (COTTERILL and JACKSON, 1989; ADAMS and JOYCE, 1990; BorRalHO et al., 1992).

The objectives of this study were to (1) optimise and compare benefit of a single-stage selection strategy based on progeny test with a two-stage selection strategy based on phenotypic pre-selection followed by progeny test for variable age of mating for progeny test, and (2) assess the effect of genetic parameters, time and cost components on the optimum age of phenotypic pre-selection and relative efficiency of the phenotypic preselection.

\section{Material and Methods}

\subsection{The breeding strategies and simulation model}

The long-term breeding programme studied was assumed to consist of multiple breeding populations of 50 members each. Within each breeding population, the breeding is carried out by double-pair mating among the 50 members (50 full-sib families obtained) and selection of a single best individual within each full-sib family as a parent for the following breeding cycle (e.g. DANELL, 1993). Our study deals with optimisation of one breeding cycle of one of these breeding populations. Annual progress in group merit of the following strategies was compared:

- Single-stage selection Progeny strategy (note, that early flowering is very beneficial for this strategy). An equal number of individuals is produced from each of the 50 full-sib families, which are obtained by double-pair mating among the 50 breeding population members. These individuals are progeny tested (open-pollinated or polycross; equal number of progeny from each individual) and a single best individual is selected within each full-sib family based on the performance of its progeny.

- Two-stage selection Phenotype / Progeny strategy (note, that for this strategy, the benefit of early flowering can be outweighed by the phenotypic pre-selection). An equal number of individuals is produced from each of the 50 full-sib families, which were obtained by double-pair mating among the 50 breeding population members. Then selection is carried out in two stages: stage 1: phenotypic pre-selection of an equal number of candidates from each of the 50 full-sib families in a phenotype test. Stage 2: progeny testing of the pre-selected candidates: planting an equal number of open-pollinated or polycross progeny from each candidate in a new test, after assessment of which, a single best individual is selected within each full-sib family based on the performance of its progeny.

When we use a two-stage selection, we use the term preselection for the first stage of the two- stage selection (preselection of individuals, which will be progeny-tested), while selections can be seen as a final stage of the two-stage selection.

No G x E interaction, change of heritability over time or epistatic variance were considered. Mean breeding value of the founders was set to zero. The infinitesimal genetic model was assumed. It was assumed that selection would be performed on the same trait or index at selection stages 1 and 2. Phenotypic pre-selection does not improve benefit from clonal testing (DANUSEVIČIUS and LINDGREN, 2002b). Therefore, the strategy based on clonal testing proceeded by phenotypic pre-selection was not included in this study.

A MS Excel-based deterministic simulator BREEDING CYCLE ANALYZER was used (available at www.genfys.slu.se/ staff/dagl). The simulations were run by the main scenario (reflecting common parameters for northerly conifers) and alternative scenarios (to test the effect of variable parameters) (Table 1). While testing an alternative value of a parameter, all the other parameters were kept at the values applied in the main scenario. In addition, an interactive scenario was constructed to simulate less favourable conditions for the phenotypic pre-selection in the two-stage strategy (low heritability, weaker J-M correlation and long rotation, Table 1). Each scenario was tested and optimised at a range of ages of mating for progeny test (assuming that at this age sufficient flowering capacity for progeny test is reached).

As selection is completely balanced and the same number of full-sib individuals and half-sib test plants are assumed for each of the 50 full-sib families, the comparisons were based on setting cost components for one full-sib family and the budget constraint was expressed per full-sib family (breeding population member) and year.

Annual progress in Group Merit $(G M / Y)$ was the value to be maximised by optimising testing time and family size in phenotype and progeny tests at a budget constraint of one complete breeding cycle:

$$
G M / Y=(G-c \Theta) / T_{C Y C L E},
$$

where $G M$ is Group Merit obtainable from selection, $G$ is estimated additive genetic gain at rotation age (cumulative for two stages), $c$ is a weighting factor between loss of genetic diversity and genetic gain that converts gain and diversity to the same percentage scale ( $c$ was set to 100 , which means that a $1 \%$ change in genetic gain is equally important as $1 \%$ change in gene diversity, thus group coancestry causes as much reduction in performance value as the same coefficient of inbreeding), $T_{C Y C L E}$ is cycle time, and $\Theta$ is the diversity loss (rise in group coancestry) per breeding cycle, which, assuming that each parent contributes two offspring for use as parents in the next breeding cycle, was estimated as:

$$
\Theta=0.25 / n \text {, }
$$

where $n$ is breeding population size $(\mathrm{n}=50)$.

Group coancestry is one of the most relevant diversity measures in optimising tree breeding strategies (LINDGREN et al., 1997 and review by Rousset, 2002). Rise in group coancestry per breeding cycle is dependent only on the breeding population size. However, the cycling time may vary depending on the breeding strategy and, thus, increase of group coancestry per unit time may vary.

Genetic gain at rotation age from within-family selection was predicted according to the following formulas (LINDGREN and WERNER, 1989):

Selection based on phenotype:

$$
G=\frac{\sigma_{A m} r_{j-m} i \sigma_{A}}{\sqrt{\sigma_{A}^{2}+\sigma_{D}^{2}+\sigma_{E}^{2}}}
$$

Selection based on half-sib progeny test:

$$
G=\frac{\sigma_{A m} r_{j-m} i 0.5 \sigma_{A}}{\sqrt{0.25 \sigma_{A}^{2}+\frac{0.75 \sigma_{A}^{2}+\sigma_{D}^{2}+\sigma_{E}^{2}}{n}}}
$$

where $G$ is additive genetic gain (\%), $\sigma_{A}^{2}$ is additive variance, $\sigma_{D}^{2}$ is dominance variance, $\sigma_{E}^{2}$ is environmental variance, $n$ is number of plants per family, $\sigma_{A m}$ is standard deviation in breeding value of the selected individuals for the target trait at rotation age, given as a percentage of the average breeding value of the unimproved individuals (one standard deviation is equal to $10 \%$, so that it converts the genetic gain values to per- 


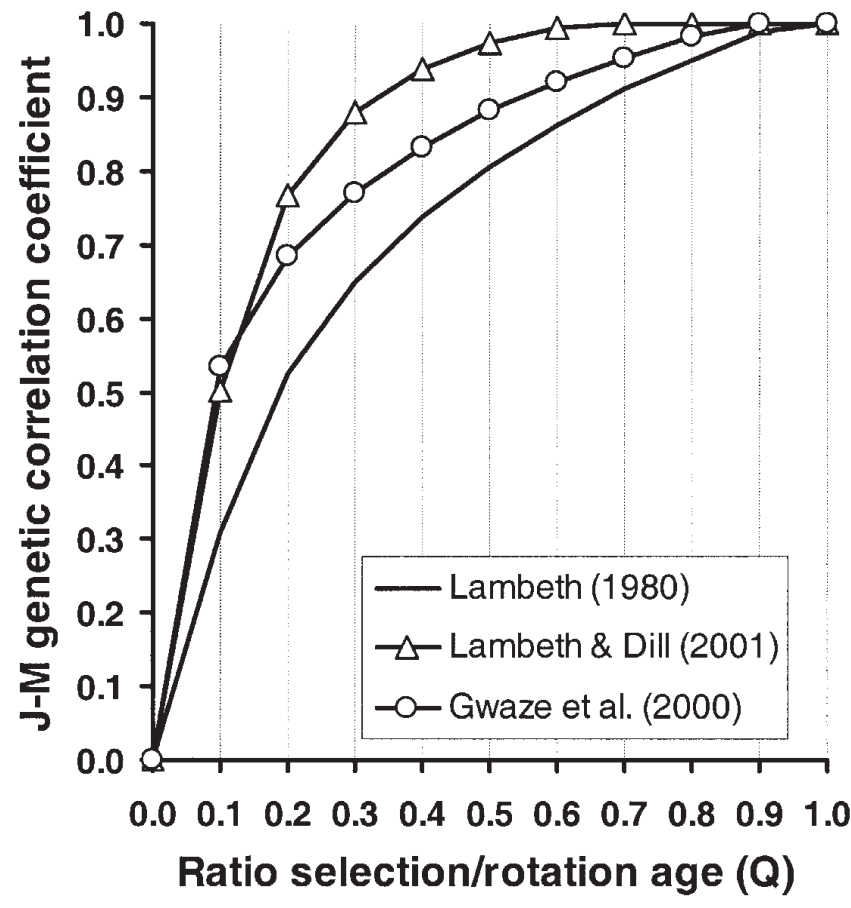

Figure 1. - Plot of the three alternative functions used to predict J-M genetic correlation.

centage scale), $i$ is selection intensity estimated in units of standard deviation of the mean of the selected individuals from the family mean by using an approximation by BuRRows (1975), and $r_{j-m}$ is juvenile-mature (J-M) genetic correlation, predicted according to the following three functions $(\mathrm{Q}$ is ratio of selection age to rotation age) (Fig. 1):

1. LAMBETH (1980) based on phenotypic family mean correlation coefficients in numerous trials with several temperate and boreal conifer species (abbreviated as "L (1980)"):

$$
r_{j-m}=1.02+0.308 * \log (Q)
$$

2. GWAZE et al. (2000) based on genetic correlation coefficients estimated in 19 trials with a total of 190 families of Pinus taeda from western USA. From the other functions available in GWAZE et al. (2000) study, we have chosen this function as predictions based on it favour very early selection (abbreviated as "G (2000)"):

$$
r_{j-m}=1.03+0.215 * \log (Q)
$$

with an adjustment for the ratio of selection age to rotation age $(Q)$ being close to 0 or 1 , applied to make the $r_{j-m}$ function more linear if the trait is measured at a very young age or an age close to rotation.

3. LAMBETH and Dill (2001) based on genetic correlations coefficients estimated in 4 series with a total of 15 trials of Pinus taeda (296 families in total). This function was constructed by pooling "within-series" functions (abbreviated as "L (2001)")

$$
r_{j-m}=1.02-0.098 *(\log (Q))^{2} .
$$

\subsection{The input values}

The initial additive variance within family was set constant to 1 (which makes 2 in the breeding population) and the dominance and environmental variances were expressed as ratios of the additive variance (Table 1). Narrow-sense heritability and dominance variance were varied by changing the environmental variance. Additive standard deviation at mature age and diversity loss were kept constant at main scenario values (Table 1).
Table 1. - Parameter values for the main, interactive and alternative scenarios. Costs are expressed per breeding population member. Parameters for the interactive scenario were chosen to disfavor the twostage strategy. Each scenario was tested and optimized to return maximum annual group merit at a range of age of mating for progeny test from 3 to 25 years.

\begin{tabular}{lccc}
\hline \multicolumn{1}{c}{ Parameters } & $\begin{array}{c}\text { Main scenario } \\
\text { values }\end{array}$ & $\begin{array}{c}\text { Alternative } \\
\text { scenario values* }\end{array}$ & $\begin{array}{c}\text { "Pro-progeny" } \\
\text { scenario values }\end{array}$ \\
\hline Additive variance $\left(\sigma_{A}{ }^{2}\right)$ & 1 & - & - \\
$\begin{array}{l}\text { Dominance variance, } \% \text { of the additive variance } \\
\left(\sigma_{D}{ }^{2}\right)\end{array}$ & 25 & $0 ; 100$ & - \\
$\begin{array}{l}\text { Narrow-sense heritability }\left(h^{2}\right) \text { (obtained by } \\
\left.\text { changing } \sigma_{E}^{2}\right)\end{array}$ & 0.1 & $0.01 ; 0.5$ & 0.01 \\
Additive standard deviation at mature age $\%$ & 10 & - & - \\
Diversity loss per cycle, $\%$ & 0.5 & - & - \\
J-M genetic correlation function & $\mathrm{L}(2001)$ & $\mathrm{L}(1980) ; \mathrm{G}(2000)$ & $\mathrm{L}(1980)$ \\
Age of mating for progeny test (age of sufficient & 3 to 25 by 1 & - & - \\
flowering capacity for progeny testing), years & & & - \\
Crossing lag for progeny test (crossing; seed & 3 & $5 ; 8$ & - \\
maturation, seedling production), years & 50 & $20 ; 30 ; 80$ & 80 \\
Rotation age $(R A)$, years & 30 & $0 ; 100$ & - \\
Recombination cost $\left(C_{R E C O M B}\right), \$$ & 1 & $0.1 ; 10$ & - \\
Cost per genotype $(C g), \$$ & 1 & $0.1 ; 2$ & - \\
Cost per plant $(C p), \$$ & 10 & $5 ; 20$ & - \\
Budget per year and parent, $\$$ (the constraint) & & To be maximized & \\
Annual progress in Group Merit $(G M / Y)$ & & & - \\
\hline
\end{tabular}

* While an alternative scenario value for any parameter was tested, all the other parameters were kept at their main scenario values.

The total cost per cycle and breeding population member was calculated as:

$$
C_{P E R C Y C L E}=C_{R E C O M B}+n\left(C_{G}+m C_{P}\right) \text {, }
$$

where $C_{R E C O M B}$ is the cost for recombination among the breeding population members, $C_{G}$ is cost per genotype, i.e. cost dependent on the type of reproductive material used (genotypedependent cost, assumed to cover: production of female parents, polycross or open-pollination, seed collection, seed extraction.), $C_{P}$ is cost per test plant (plant-dependent cost, assumed to cover production of test plants, establishment and maintenance of the selection test), $n$ is number of genotypes (female parents for progeny test) and $m$ is number of plants (number of seedlings per family in progeny test).

Genotype-dependent costs were assumed to cover production of female parents (maintenance, polycross, seed extraction). Plant-dependent costs were assumed to cover production of the test plants in the nursery as well as establishment, maintenance and assessment of the selection test. The costs were expressed in " $\$$ ", which can be interpreted as "cost-units". The basis for setting the costs was as follows: cost per test plant (plant-dependent cost) was set to $1 \$$ and the other costs were expressed in ratios of $1 \$$ (Table 1). Cost was assumed to be independent of the testing time.

The simulations were run with a total budget constraint expressed per breeding population member and year.

The time per breeding cycle was subdivided into the following components:

$$
T_{\text {CYCLE }}=T_{\text {RECOMB }}+T_{\text {MATING }}+T_{\text {LAG }}+T_{\text {PRTEST }}
$$

where $T_{R E C O M B}$ is the time for recombination among breeding population members, $T_{\text {MATING }}$ is age of mating for progeny test, i.e. it is the age of sufficient flowering capacity to initiate progeny test (for the two-stage strategy it corresponds to the age of phenotypic pre-selection in the 1st stage test (i.e. phenotype testing time)), $T_{L A G}$ is crossing lag for progeny test (polycross, seed maturation, seedling production), $T_{P R T E S T}$ is progeny testing time (to be optimised at a given value of $T_{\text {MATING }}$ ).

$T_{\text {RECOMB }}$ was fixed to 3 years for all scenarios. $T_{\text {MATING }}$ was varied from age 3 to 25 by one year and the strategies were 
optimised for each age value in this range (for the Phenotype/Progeny strategy, age of mating for progeny test was assumed to be identical with phenotypic pre-selection age and age of sufficient flowering capacity for progeny testing). Progeny of Scots pine and Norway spruce usually acquire a sufficient flowering capacity for progeny testing at age 15 and 25, respectively (ALMQVIST, 2001). $T_{L A G}$ was varied from 3 (main) to 5 and 8 years (alternative scenarios).

\section{Results}

For all the scenarios except the interactive, the two-stage Phenotype/Progeny strategy at the optimum age of mating for progeny test (phenotypic pre-selection age) generated higher $G M / Y$ than the single-stage Progeny strategy with the progeny test initiated at age 3 (Table 2). For the interactive scenario (low heritability, long rotation, weak J-M correlation), the single-stage strategy became superior to the two-stage strategy at age of mating for progeny test of 9 years and earlier (Table 2, Figure 2).

Low narrow-sense heritability, weak J-M genetic correlation, long rotation age, high test plant cost and low budget favoured the single-stage Progeny strategy (Figures 2 to 4). Narrowsense heritability had the strongest effect (Figure 3). Variation in dominance variance, crossing lag, recombination cost and cost per genotype had no marked effect on ranking between the strategies (Table 2). In comparison with L(1980), G(2000) and $\mathrm{L}(2001) \mathrm{J}-\mathrm{M}$ correlation functions returned higher correlation coefficients, leading to an earlier optimum selection age, which was in favour of the two-stage strategy (Table 2, Figures 2 to 4). The highest $G M / Y$ was generated by L(2001) (Figure 3). In

Table 2. - Comparison of annual progress in Group Merit $(G M / Y)$ from the single-stage Progeny strategy at age of mating for progeny test equal to 3 years (sufficient flowering capacity reached at age 3 ) and the two-stage Phenotype / Progeny strategy at the optimum age of mating for progeny test (optimum age of phenotypic-pre-selection in stage 1). Maximum GM/Y from the main, interactive and alternative scenarios is given. For the two-stage strategy, the \% of GM/Y lost from the optimum due to delay of mating for progeny test until age 15 or 25 years is given in the last two columns.

\begin{tabular}{|c|c|c|c|c|c|c|c|c|c|c|c|c|c|c|}
\hline \multirow{3}{*}{ Parameter } & \multirow{3}{*}{ Value } & \multicolumn{5}{|c|}{$\begin{array}{l}\text { Single-stage Progeny at age of } \\
\text { mating for the test }=3 \text { years }\end{array}$} & \multicolumn{8}{|c|}{$\begin{array}{l}\text { Two-stage Phenotype/Progeny at optimum age of mating for } \\
\text { progeny test (=phenotypic pre-selection age) }\end{array}$} \\
\hline & & \multirow[t]{2}{*}{$\begin{array}{l}\text { Test } \\
\text { time, } \\
\text { years }\end{array}$} & \multirow[t]{2}{*}{$\begin{array}{c}\text { Fa- } \\
\text { mily } \\
\text { size } \\
0^{0} / 0^{b}\end{array}$} & \multirow[t]{2}{*}{$\begin{array}{l}\text { Cycle } \\
\text { gain, } \\
\%\end{array}$} & \multirow[t]{2}{*}{$\begin{array}{l}\text { Cycle } \\
\text { time, } \\
\text { years }\end{array}$} & \multirow[t]{2}{*}{$\underset{\%}{\mathrm{GM} / \mathrm{Y}}$} & \multirow[t]{2}{*}{$\begin{array}{l}\text { Age at } \\
\text { mating } \\
\text {, years }\end{array}$} & \multirow[t]{2}{*}{$\begin{array}{c}\text { Family } \\
\text { sizes } \\
0^{1} / 0^{2} / 0^{3}\end{array}$} & \multirow[t]{2}{*}{$\begin{array}{l}\text { Gain } \\
\text { stage } \\
1, \%\end{array}$} & \multirow[t]{2}{*}{$\begin{array}{l}\text { Gain } \\
\text { stage } \\
2, \%\end{array}$} & \multirow[t]{2}{*}{$\begin{array}{l}\text { Cycle } \\
\text { time, } \\
\text { years }\end{array}$} & \multirow[t]{2}{*}{$\begin{array}{l}\mathrm{GM} / \mathrm{Y} \\
\%\end{array}$} & \multicolumn{2}{|c|}{$\begin{array}{c}\% \text { of } \mathrm{GM} / \mathrm{Y} \\
\text { lost: optimum } \\
\text { versus mating } \\
\text { age of }\end{array}$} \\
\hline & & & & & & & & & & & & & 15 & 25 \\
\hline & Table 1 & 13 & $7 / 26$ & 5.8 & 22 & 0.240 & 10 & $5 / 72 / 32$ & 3.2 & 4.6 & 27 & 0.274 & 3 & 15 \\
\hline $\begin{array}{l}\text { "Pro- } \\
\text { progeny" } \\
\text { scenario }\end{array}$ & ble 1 & 56 & $6 / 101$ & 3.8 & 65 & 0.051 & 17 & $6 / 69 / 103$ & 0.7 & 3.4 & 72 & 0.049 & 0 & 1 \\
\hline \multirow{2}{*}{$\begin{array}{l}\sigma_{p}^{2}, \% \text { of } \\
\sigma_{A}^{2}\end{array}$} & 0 & 14 & $7 / 27$ & 5.9 & 23 & 0.239 & 10 & $5 / 71 / 33$ & 3.1 & 4.7 & 27 & 0.272 & 3 & 15 \\
\hline & 100 & 14 & $7 / 27$ & 6.1 & 23 & 0.246 & 10 & $6 / 72 / 27$ & 3.1 & 5.0 & 27 & 0.281 & 3 & 15 \\
\hline \multirow[t]{2}{*}{$h^{2}$} & 0.01 & 20 & $5 / 51$ & 2.7 & 29 & 0.075 & 11 & $5 / 58 / 46$ & 1.0 & 2.1 & $32 \quad$ & 0.081 & 1 & 8 \\
\hline & 0.5 & 12 & $16 / 10$ & 10.1 & 21 & 0.465 & 10 & $5 / 116 / 16$ & 9.3 & 5.7 & 23 & 0.627 & 4 & 18 \\
\hline \multirow{2}{*}{$\begin{array}{l}\text { J-M } \\
\text { correla-tion }\end{array}$} & $\mathrm{L}(1980)$ & 22 & $8 / 34$ & 6.1 & 31 & 0.180 & 12 & $7 / 81 / 36$ & 2.3 & 5.3 & 37 & 0.191 & 1 & 6 \\
\hline & $\mathrm{G}(2000)$ & 13 & $7 / 26$ & 5.1 & 22 & 0.208 & 7 & $5 / 56 / 25$ & 2.3 & 3.5 & 220 & 0.247 & 6 & 16 \\
\hline \multirow{3}{*}{$\begin{array}{l}\text { Rotation } \\
\text { age, years }\end{array}$} & 20 & 8 & $6 / 22$ & 5.6 & 17 & 0.306 & 0 & $4 / 51 / 22$ & 3.5 & 3.8 & 17 & 0.389 & 14 & 29 \\
\hline & 30 & 10 & $7 / 22$ & 5.8 & 19 & 0.278 & 8 & $5 / 60 / 24$ & 3.4 & 4.4 & 22 & 0.338 & 9 & 23 \\
\hline & 80 & 20 & $8 / 31$ & 6.3 & 29 & 0.204 & 13 & $6 / 85 / 38$ & 2.9 & 5.3 & $35 \quad$ & 0.220 & 0 & 8 \\
\hline \multirow{2}{*}{$\begin{array}{l}\text { Crossing } \\
\text { lag, years }\end{array}$} & 5 & 14 & $8 / 27$ & 6.3 & 25 & 0.230 & 10 & $6 / 74 / 31$ & 3.1 & 5.2 & 30 & 0.263 & 3 & 14 \\
\hline & 8 & 15 & $8 / 32$ & 6.9 & 29 & 0.216 & 10 & $6 / 82 / 35$ & 3.1 & 5.5 & 33 & 0.248 & 2 & 12 \\
\hline \multirow{2}{*}{$\begin{array}{l}\text { Recombi- } \\
\text { nation cost, } \\
\$\end{array}$} & 0 & 13 & $7 / 30$ & 6.0 & 22 & $\overline{0.255}$ & 9 & $6 / 72 / 30$ & 2.9 & 5.0 & 26 & 0.286 & 4 & 16 \\
\hline & 100 & 19 & $7 / 25$ & 6.3 & 28 & 0.205 & 12 & $5 / 64 / 27$ & 3.4 & 4.6 & 30 & 0.245 & 1 & 10 \\
\hline \multirow{2}{*}{$\begin{array}{l}\text { Cost per } \\
\text { test plant, \$ }\end{array}$} & 0.1 & 11 & $17 / 91$ & 10.5 & 20 & 0.4 & 6 & $\begin{array}{c}14 / 327 / \\
104\end{array}$ & 2.4 & 9.8 & 22 & 0.528 & 11 & 25 \\
\hline & 2 & 15 & $6 / 17$ & 4.8 & 24 & 0.179 & 11 & $4 / 46 / 19$ & 3.1 & 3.3 & 28 & 0.213 & 2 & 11 \\
\hline \multirow{2}{*}{$\begin{array}{l}\text { Cost per } \\
\text { test } \\
\text { genotype, \$ }\end{array}$} & 0.1 & 14 & $8 / 25$ & 6.1 & 23 & 0.244 & 10 & $6 / 72 / 28$ & 3.0 & 4.9 & $27 \mathrm{C}$ & 0.276 & 4 & 15 \\
\hline & 10 & 15 & $5 / 31$ & 5.5 & 24 & 0.213 & 11 & $4 / 69 / 35$ & 3.4 & 4.2 & 28 & 0.256 & 2 & 12 \\
\hline \multirow{2}{*}{$\begin{array}{l}\text { Annual } \\
\text { budget, } \$\end{array}$} & 5 & 19 & $6 / 17$ & 5.0 & 28 & $\overline{0.165}$ & 12 & $4 / 44 / 17$ & 3.2 & 3.2 & 29 & 0.201 & 1 & 9 \\
\hline & 20 & 12 & $9 / 43$ & 7.4 & 21 & 0.323 & 8 & $7 / 111 / 49$ & 2.9 & 6.3 & 25 & 0.354 & 6 & 19 \\
\hline
\end{tabular}

a full-sib family size, ${ }^{\mathrm{b}}$ half-sib family size for the progeny test; ${ }^{1}$ number of phenotypically pre-selected trees per full-sib family, ${ }^{2}$ full-sib family size for the phenotypic pre-selection, ${ }^{3}$ half-sib family size for the progeny test. comparison with L(2001), G(2000) function forced a more early optima for the selection age (Table 2, compare the functions in Figure 1). This resulted in lower J-M correlations, lower selection intensity (less genetic gain) but, on the other hand, in a

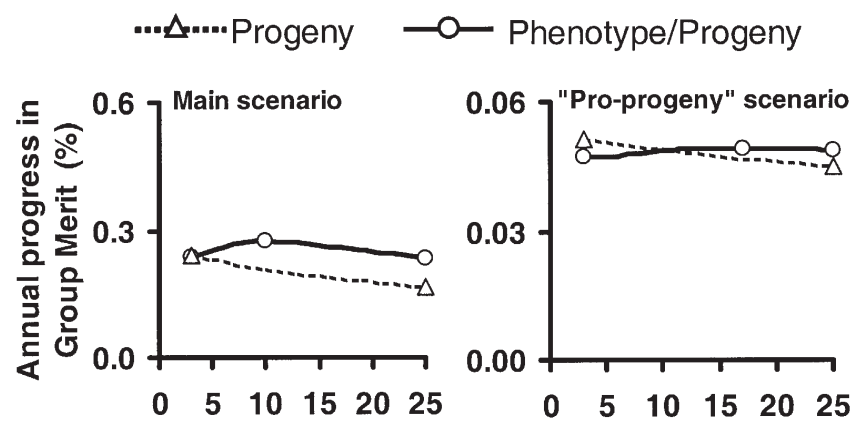

Age of mating for progeny test (years)

Figure 2. - Annual progress in Group Merit $(G M / Y)$ from the singlestage Progeny and the two-stage Phenotype/Progeny strategies plotted against the age of mating for the progeny test. The testing time and test size were optimised to return maximum $G M / Y$ at each unit change in age of mating for progeny test. For the main scenario, the parameter values are typical for northerly conifers. For the interactive scenario, the parameter values were chosen to disfavour the phenotypic pre-selection $\left(\mathrm{h}^{2}=0.01\right.$, low J-M correlation by L $(1980)$, rotation age $\left.=80\right)$. For the two-stage strategy, the marker in the middle points at the optimum age of mating for progeny test.

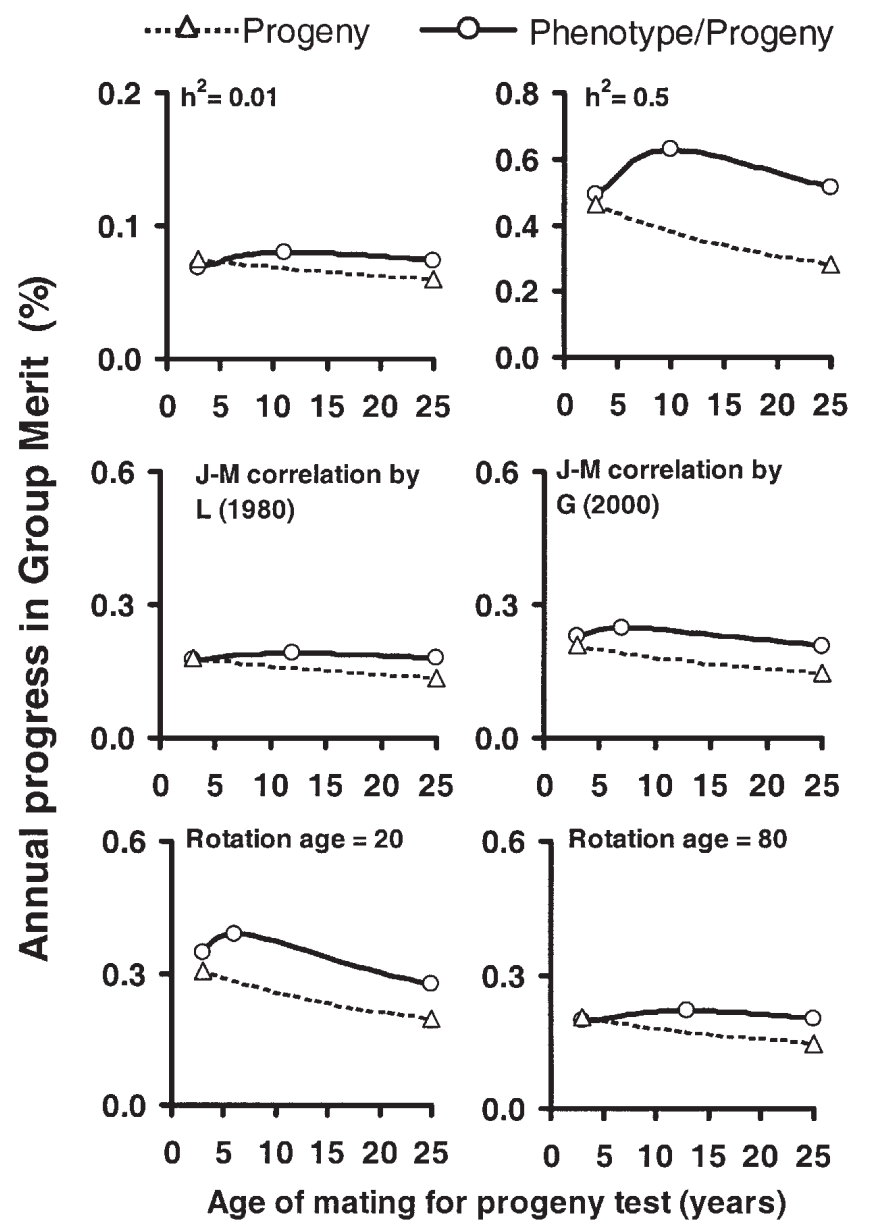

Figure 3. - The strategies compared at alternative values of genetic and time components (heritability, appearance of juvenile-mature correlation over age, and rotation time). The testing time and test size were optimised to return maximum $G M / Y$ at each unit change in age of mating for progeny test. For the two-stage strategy, the marker in the middle points at the optimum age of mating for progeny test. 


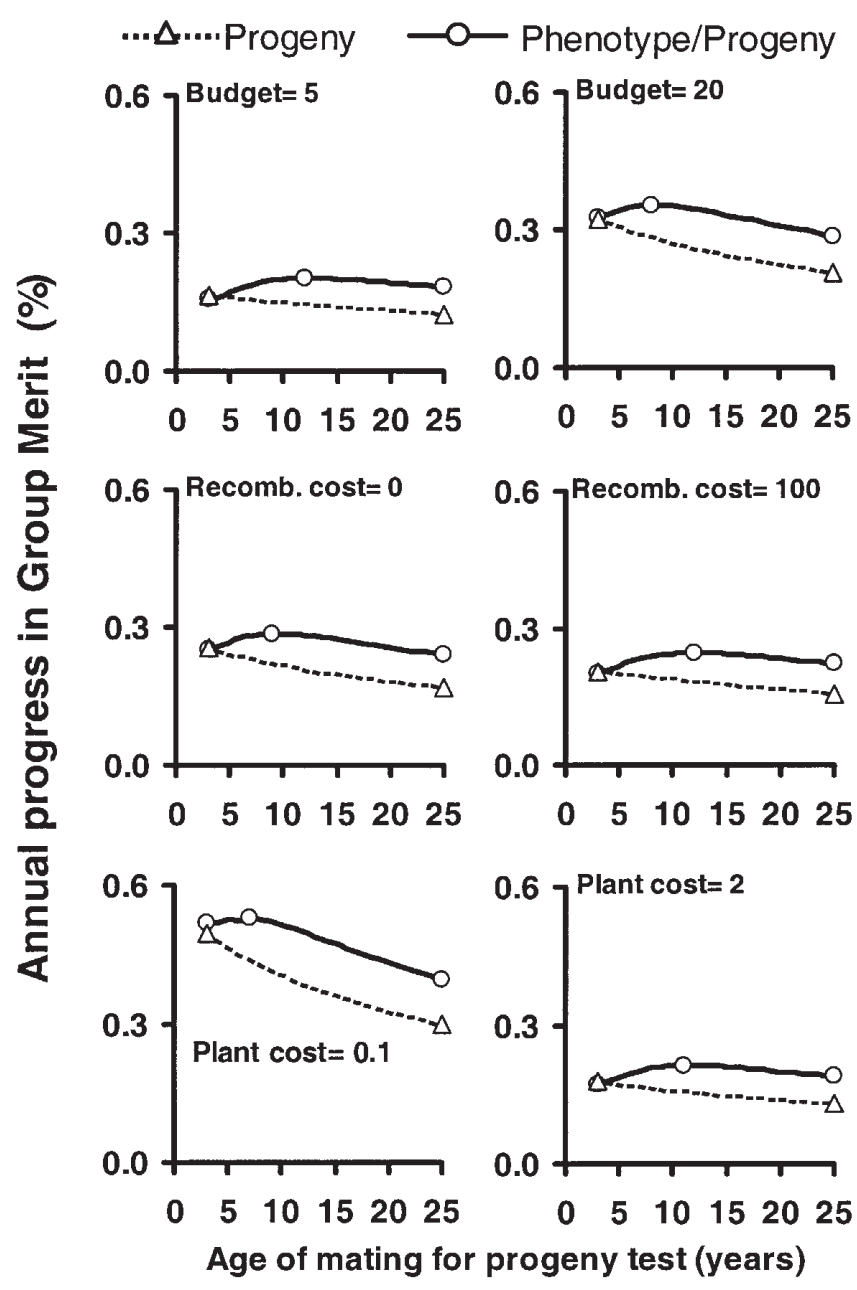

Figure 4. - The strategies compared at alternative values of cost components (annual budget, recombination cost, plant dependent cost). The testing time and test size were optimised to return maximum $G M / Y$ at each unit change in age of mating for progeny test. For the two-stage strategy, the marker in the middle points at the optimum age of mating for progeny test.

shorter cycle time, which, however, was not short enough to return higher gain per unit time than from scenario with $\mathrm{L}$ (2001) function (Table 2).

For the two-stage Phenotype / Progeny strategy, the optimum age of mating for progeny test (phenotypic pre-selection age) was 10 years for the main scenario and varied from 6 (rotation age is 10) to 17 years (interactive scenario) (Table 2). The optimum age of mating for progeny test age was mainly affected by variation in J-M correlation, rotation age, annual budget, cost of recombination and cost of test plants (Table 2). The percentage of $G M / Y$ lost from the optimum due to the delay of mating for progeny test until age 15 or 25 years varied from 0 to 14 and from 1 to 29 , respectively (Table 2). The reduction of $G M / Y$ due to the delay of mating for progeny test was relatively greater in case of high heritability, short rotation, high budget and low plant cost (Table 2, Figures 2 to 4). Whereas, for the interactive scenario and the alterative scenarios with low heritability, low J-M correlation, long rotation, low annual budget and high recombination as well as test plant costs, the $G M / Y$ reduction was minor (Table 2, Figures 2 to 4). Variation in heritability, rotation age, total budget and plant cost markedly affected reduction of $G M / Y$ due to the delay. Whereas, variation in dominance variance, crossing lag, recombination and genotype dependent costs had no marked effect (Figures 2 to 4 ).

\section{Discussion}

\subsection{Pre-selection versus early flowering}

The most important finding of this study is that for a longterm breeding strategy based on progeny testing, investment in phenotypic pre-selection, in most cases, is more beneficial than investment to achieve early flowering in a single-stage progeny test. Evidently, while waiting for sexual maturity of the candidates, the phenotypic pre-selection generated higher gain per unit time than progeny test at its highest capacity, i.e. at a very early flowering scenario (Table 2). Gain generating efficiency of the first-stage phenotypic pre-selection was noted e. g. by NAMkoONG (1970) and BorralHo et al. (1992). This relative advantage of the phenotypic pre-selection mainly depends on heritability, strength of J-M genetic correlation and rotation age (WU, 1998; DANUSEVIČIUS and LINDGREN, 2002b).

Choice of the single-stage Progeny strategy with an investment to achieve early flowering may be motivated under conditions which disfavour phenotypic selection. These are low heritability, long rotation, weak J-M correlation (the interactive scenario, Figure 2). Then it would be necessary to achieve sufficient flowering capacity of the candidates at least at age 9 .

High heritability strengthens gain-generating capacity of phenotypic pre-selection, which allows the two-stage strategy to provide a relatively greater gain per unit time (DANUSEvičIUS and LindGREN, 2002b). On the contrary, long rotation makes the phenotypic pre-selection less beneficial through lower J-M genetic correlation at the optimum selection age. This gives a relative advantage to the single-stage Progeny strategy. GwAzE et al. (2000) and LAMBETH and DiLL (2001) and J-M correlation functions returned higher correlation coefficients, which favoured the two-stage strategy. Higher J-M correlation coefficients resulted in an earlier optimum for the pre-selection age, which, in terms of gain generating efficiency, was more favourable for the two-stage strategy. For instance, in the scenario with heritability of 0.1 , rotation age of 50 and GwAZE et al. (2000) J-M correlation function, there was no difference in cycle time between the two strategies (Table 2).

The annual budget constraint may vary widely among breeding programmes. We have tested what we believe is a reasonable range for the most commercially important conifers. If calculations with more case-specific parameters are needed, the tool we offer on the internet can be used. However, we suggest that the main results often will be similar to ours and will extend well beyond the variants of Swedish conifer breeding, which we considered when assigning the parameter values.

Discounting to calculate comparable "present values" of activities done at different times is hardly applicable to longterm breeding. The long-term breeding is thought as a cyclic phenomenon and the costs are calculated for the complete cycle and the long-term breeding should continue for many such cycles. There is no assumption of where in the cycle the breeding is actually operating, which is needed to get present values. Discounted value consideration for long-term breeding probably becomes interesting first if it is linked to assumptions about when and how the long-term breeding will result in plants used in forestry, and this study does not consider that.

In this study, narrow-sense heritability in the breeding population was assumed to be constant. However, heritability may increase with age (e.g. MAGNUSSEN, 1993; JoHnson et. al., 1997). This would favour phenotypic pre-selection followed by progeny testing (DANUSEviČIUS and LINDGREN, 2002b) and, thus, strengthen our conclusions. We have also assumed that the plant cost is independent of the duration of the test. However, a more complicated model could be used, assuming plants are cheaper if testing time is short. That would favour selec- 
tions at an earlier age, and it seems possible singe-stage progeny test initiated at an earlier age (thus flowering stimulation) would appear as a more competitive alternative.

Our findings are based on a fair and complete comparison as it ranked the strategies by considering genetic gain, diversity loss, cost and time simultaneously. There are no earlier studies on optimisation of tree breeding strategies which accounts for all the parameters listed above simultaneously. It should also be noted that progeny testing is not the only testing strategy available to maximise benefit of balanced within-family selection. DANUSEviČIUS and LINDGREN (2000b) suggested that a testing strategy based on single-stage clonal test is by far the best, except for traits with very high heritability, where singlestage phenotype strategy is superior. Thus, phenotypic preselection would be of relevance for the species which are difficult to clone and where it is considered important to have genotypes with accurately determined breeding values (relies on progeny test, e.g. Scots pine). In case of low budget, high heritability and high test plant cost, a single-stage selection based on phenotype alone may provide adequate or higher benefit than single-stage Progeny or two-stage Phenotype/Progeny strategy (DANUSEVIČIUS and LINDGREN, 2002b).

\subsection{Optimum age of mating for progeny test in the two-stage strategy}

To obtain maximum benefit from the two-stage Phenotype / Progeny strategy, the candidates should possess sufficient flowering capacity at the optimum age of mating for progeny test (age of phenotypic pre-selection). In case of common parameters for northerly conifers (the main scenario), the optimum phenotypic pre-selection age was 10 years. Thus, it would be beneficial to fasten their sexual maturation to about age of 10 (e.g. Scots pine progeny usually reach sufficient flowering capacity for progeny testing at about age 15, ALMQUIST (2001)). If rotation is short, J-M correlation strong or testing is expensive, sufficient flowering capacity is desirable already at age of 6 to 8 years.

Another important issue is how flat are the optima for the pre-selection age, i.e. is the loss of benefit large enough to motivate investment in early sexual maturity? In case of high heritability, short rotation, high budget and low plant cost, the reduction of $G M / Y$ due to the delay in mating for progeny test until age 25 would be 18 to $25 \%$, which may be an important loss. However, in case of low heritability, low J-M correlation, long rotation, low annual budget or high test plant cost, the optima for pre-selection age were rather flat (Figures 2 to 4 ): loss of $G M / Y$ would be 6 to $11 \%$ of the optimum, which may be an acceptable figure. If mating for progeny test would be delayed to age 15 , no marked loss of $G M / Y$ would occur (1 to $6 \%$ ) for any reasonable parameter value, except for short rotation and cheap testing (i.e. where very early selection is favourable). As crossing lag and genotype-dependent costs had no marked effect on $G M / Y$ lost from the optimum, the crosses can be made over a longer time to simultaneously test all preselected individuals and their flowering may be induced at a higher cost.

The optimum age of mating for progeny test mainly depends on the efficiency of the phenotype test to generate enough gain per unit time to motivate a prolongation of the testing for an additional unit of time. This gain generating efficiency is mainly reflected by the slope of the J-M genetic correlation function. The slopes of GWAZE et al. (2000) and LAMBETH and Dill (2001) functions, being steeper than that of LAMBETH (1980) function, forced an earlier optimum pre-selection age (Table 2). Threshold values in the slope of J-M correlation functions may also approximately indicate the optimum age of selection. For instance, for LAMBETH and DiLL (2001) function, this threshold in the slope occurs at about 0.2 of the rotation age (10 years at rotation 50, Fig. 1), which is the optimum pre-selection age for the main scenario (Table 2). JoHnson et al. (1997) and XIE and YANCHUK (2002) obtained similar optima for selection age in tree species with heritability at about 0.1 and rotation age of 60. LAMBETH (1980) concluded that selection at age 5 to 6 years was optimal for rotation of 20 and selection at age 7 to 8 years when rotation was 50 years. The optimum age of mating for progeny test age was also affected by rotation age (an adequate effect as of J-M correlation) and cost components. Expensive testing or low budget mean that the resource allocation within the two-stage strategy would be more efficient when the relatively cheaper phenotype test is given a stronger testing effort (leading to a longer phenotype test time).

\subsection{Concluding remarks}

If the task is to maximise the long-term benefit from a breeding strategy based on progeny testing (1) two-stage selection strategy consisting of phenotypic pre-selection followed by progeny test returns greater benefit per unit time than singlestage progeny test strategy with a very early flowering opportunity, (2) for common parameters of northerly conifers, the optimum age of mating for the progeny test in the two-stage strategy was 10 years (flowering induction at age 10 is desirable), but the disadvantage to wait until the age of 15 years (because of limited flowering) was minor, and (3) the situation where it may be worth to consider single-stage progeny test with a benefit-motivated investment in a very early flowering is when heritability is very low ( 0.01$)$, J-M genetic correlations are not strong and rotation is long ( 80 years).

\section{Acknowledgements}

We gratefully acknowledge "Carl Tryggers stiftelse" and "Kempestiftelserna" for financial support. We acknowledge discussions with CLEM LAMBETH and CURT AlmQVist.

\section{References}

AdAms, W. T. and Joyce, D. G.: Comparison of selection methods for improving volume growth in young coastal Douglas-fir. Silvae Genet. 39: 219-226 (1990). - AlmQVIST, C. and EkBERG, I.: Interstock and GA4/7 effects on flowering after topgrafting in Pinus sylvestris. For Genet. 8: 279--284 (2001). - Barnes, R. D., Mullin, L. J. and Battle, G.: Genetic control of 50-th year traits in Pinus patula Schiede and Deppe. Silvae Genet. 41: 242-248 (1992). - Borralho, N. M. G., CotTERILL, P. P. and Kanowski, P. J.: Genetic control of growth in Eucalyptus globules in Portugal. II. Efficiencies of early selection. Silvae Genet. 41 70-77 (1992). - Bramlett, D. L., Williams, C. G. and BurRis, L. C. Surrogate pollen induction shortens the breeding cycle in loblolly pine. Tree Phys. 15 (7-8): 531-535 (1995). - BuRDon, R. D.: Early selection in tree breeding: Principles for applying index selection and inferring input parameters. Can J. For. Res. 19: 499-504 (1989). - BurRows, P. Variance of selection differentials in normal samples. Biometrics 31 : 125-133 (1975). - CotTerill, P. P. and JACKson, N.: Gains expected from clonal orchards under alternative breeding strategies. For. Sci. 35 183-196 (1989). - DANELL, Ö.: Breeding programmes in Sweden. In: Proc. Meeting of Nordic group of tree breeding, "Progeny testing and breeding strategies" (Ed. S. J. LEE). Oct. 1993, Edinburgh, Forestry Commission, 128 (i-v), (1993). - DANUsevičrius, D. and LindGREN, D.: Comparison of phenotypic, clonal and progeny supported selection in long-term tree breeding. Silvae Genet. 51: 19-26 (2002a). DANUSEvičIUS, D. and LindGREN, D.: Two stage selection in long-term tree breeding. For. Genet. 9: 147-159 (2002b). - FrankLIN, E.: Modeling related levels of genetic variance to stand development of four North America conifers. Silvae Genet. 28: 207-212 (1979). — GWAZE, D. P., Woolliams, J. A. and Kanowski, P. J.: Optimum selection age for height in Pinus taeda L. in Zimbabwe. Silvae Genet. 46: 358-365 (1997). - GwaZe, D. P., Bridgwater, F. E., Byram, T. D., Woolliams, J. A. and WilliaMs, C. G.: Predicting age-age genetic correlations in treebreeding programs: a case study of Pinus taeda L. Theor. Appl. Genet. 100: 199-206 (2000). - Haggman, H. M., Aronen, T. S. and Stomp, A. M.: Early-flowering Scots pines through tissue culture for accelerating 
tree breeding. Theor. Appl. Genet. 93: 840-848 (1996). — JoHNSON, G. R. SNiEzko, R. N. and MANDEL, N. L.: Age trends in Douglas-fir genetic parameters and implications for optimum selection age. Silvae Genet 46: 349-358 (1997). - KING, J. N. and BuRDON, R. D.: Time trends in inheritance and projected efficiencies of early selection in a large 17 year old progeny test of Pinus radiata. Can J. For. Res. 21: 1200-1207 (1991). - LAMBETH, C. C.: Juvenile-mature correlation in Pinaceae and implications for early selection. For. Sci. 26: 571-580 (1980). — LAMBETH, C. and Dill, L. A.: Prediction models for juvenile mature correlations for loblolly pine growth traits within, between and across test sites. For. Genet. 8: 101-108 (2001). - Lambeth, C. C., van Buitenen, J. P., McCullough, R. B and Duke, S. D.: Early selection is effective in 20 year-old genetic tests of loblolly pine. Silvae Genet. 32: 210-215 (1983) - LindGren, D. and Werner, M.: Gain generating efficiency of different Norway spruce seed orchard designs. In: Proc. IUFRO WP S2.02-11 Meeting Norway spruce; Provenances, Breeding and Genetic Conservation (Eds. L.-G. STENER and M. WERNER), Uppsala, Sweden. pp. 189-207 (1989). - LindGREN, D. and Mullin, T. J.: Balancing gain and relatedness in selection. Silvae Genet. 46: 124-129 (1997). — LINDGREN, D. GeA, L. D. and Jefferson, P. A.: Status number for measuring genetic diversity. For. Genet. 4: 69-76 (1997). - Magnussen, S.: Growth differentiation in white spruce crop tree progenies. Silvae Genet. 28: 207
212 (1993). - McKeand, S. E.: Optimum age for family selection for growth in genetic tests of loblolly pine. For. Sci. 34: 400-411 (1988). NAMKOONG, G.: Optimum allocation of selection intensity in two stages of truncation selection. Biometrics 26: 465-476 (1970). - RIEMENSCHNEIDER, D. E.: Heritability, age-age correlations, and inferences regarding juvenile selection in Jack pine. For. Sci. 34: 1076-1082 (1988). - Rosvall, O.: Enhancing gain from long-term forest tree breeding while conserving genetic diversity. Dissertation, Swedish University of Agricultural Sciences, Umeå, Sweden, Sylvestria 109, (1999). Rosvall, O., Lindgren, D. and Mullin, T. J.: Sustainability robustness and efficiency of a multi-generation breeding strategy based on withinfamily clonal selection. Silvae Genet. 47: 307-321 (1999). — ROUSSET, F.: Inbreeding and relatedness coefficients: what do they measure? Heredity 88: 371-380 (2002). - WeI, R.-P. and LindGREN, D.: Optimum breeding generation interval considering build-up of relatedness. Can J. For. Res. 31: 722-729 (2001). - Wu, H. X.: Study of early selection in tree breeding - 1. Advantage of early selection through increase of selection intensity and reduction of field test size. Silvae Genet. 47: 146-155 (1998). - XIE, C.-Y. and YANCHUK, D.: Genetic parameters of height and diameter of interior spruce in British Columbia. For. Genet. 9: 1-10 (2002).

\title{
Retrospective Evaluation of Parental Selection in Nursery Tests of Juglans regia L. Using a Mixed Model Analysis
}

\author{
By N. Aletà ${ }^{1)}$, A. Ninot ${ }^{1)}$ and J. Voltas ${ }^{2)}$
}

(Received $31^{\text {st }}$ October 2003)

\section{Summary}

Results of early testing in Juglans regia performed over the period 1993-2002 are presented. A total of 37 progenies were evaluated for establishment, growth traits, and phenology at ages one and two during two or more sowing years in the nursery. Independent culling selection was applied on parental trees to the family-mean values using specific truncation points for establishment, diameter and total height. In addition, parental selection was performed on unbiased predictions (BLUPs) of parental breeding values using a multivariate mixed model analysis in order to account for the unbalanced nature of the entire data set. Genetic parameters (heritabilities, correlations) of juvenile traits were also estimated. Except for second year growth traits, the genetic control of most characters was quite high, with heritability estimates ranging from 0.51 (establishment) to 0.93 (flushing date). Growth performance and establishment did not bear a common genetic control according to non-significant genetic correlations, but a higher growth was typical of early flushing families. Changes in parental ranking for growth after comparison of familymean and BLUP-based estimates of parental performance were considerable. This observation, together with the larger proportion of culled progenies in the former method (about 70\%), suggests a sizeable loss of genetic gain by using unadjusted parental means. It is concluded that current evaluation and selection schemes using family-mean values should be recon-

1) Institut de Recerca i Tecnologia Agroalimentàries (IRTA). Departmen of Mediterranean Trees. Centre of Mas Bové. PO. Box 415. 43280 Reus. Spain.

2) Departament de Producció Vegetal i Ciència Forestal, E.T.S.E.A Universitat de Lleida, Av. Rovira Roure 191, Lleida E-25198, Spain sidered by i) relaxing truncation points for selection on establishment and growth traits and ii) re-evaluating progeny test data using a mixed model framework to unveil valuable material otherwise neglected due to unaccounted environmental influence on family performance.

Key words: Juglans regia, early selection, genetic parameters, BLUP, mixed model.

\section{Introduction}

Persian walnut (Juglans regia L.) is still present as scattered individual trees or in small groves in Western Europe (GERMAIN et al., 1997). Trees usually grow close to houses because of their traditional use to produce edible nuts. Although anthropic selection based on nut production has occurred since ancient times (Leslie and McGranahan, 1998), the use of Juglans regia wood is comparatively recent, starting in the fourteenth century with the creation of furniture manufactories in West Europe. Currently though, there is no improved material available in commercial forest nurseries for wood production in Europe. Most plantations are in fact established using seedlings from outstanding trees selected in surrounding areas. In Italy, wild populations such as 'Bleggiana' and 'Feltrina' in the north or 'Sorrento' in the south, have been traditionally used in plantations (MALVOLTI et al., 1996), while ancient cultivars characterised by their rusticity (e.g. 'Charente', 'Lozeronne') are still being planted in France (BECQUEY, 1997).

At present, breeding activities for Juglans regia are being carried out at Mas Bové (IRTA Centre, Spain) in order to release suitable material for wood production. Parental selection is undertaken through a two-stage scheme by which early 